\title{
Novel Method to Process Cystic Fibrosis Sputum for Determination of Oxidative State
}

\author{
A. Hector F. Jonas M. Kappler M. Feilcke D. Hartl M. Griese \\ Paediatric Pneumology, Children's Hospital, University of Munich, Munich, Germany
}

\section{Key Words}

Cystic fibrosis · Dithiothreitol $\cdot$ Glutathione $\cdot$ Induced sputum

\begin{abstract}
Background: Induced sputum is the most commonly used method to analyze airway inflammation in cystic fibrosis (CF) patients ex vivo. Due to the complex matrix of the sample material, precise and reliable analysis of sputum constituents depends critically on preanalytical issues. Objectives: Here we compared the commonly used method for sputum processing by dithiothreitol (DTT) with a novel mechanical method in regard to basal cellular parameters, neutrophil markers and glutathione (GSH) levels. Methods: Sputum samples from CF patients were processed in parallel with or without the use of DTT. The key improvement of the mechanical method was the processing in many very small aliquots. Cellular and humoral markers were assessed and compared according to Bland-Altman. Results: Total cell count, cell viability, differential cell count, neutrophil elastase levels and flow cytometrically analyzed neutrophil markers (CD63, CD11b, DHR) did not differ between the two methods. Intracellular and extracellular GSH levels were significantly higher in DTT-treated samples $(p=0.002)$. Conclu-
\end{abstract}

sion: The mechanical sputum-processing method presented had a similar yield of cells and fluids as the conventional DTT method and the advantage of omitting the introduction of reducing agents. This method allows a more reliable analysis of redox-dependent airway inflammation in sputum cells and fluid from CF patients than methods utilizing DTT.

Copyright $\odot 2009$ S. Karger AG, Basel

\section{Background}

Cystic fibrosis (CF) is the most frequent hereditary disease in Caucasians [1] caused by mutations in the CFTR (cystic fibrosis transmembrane conductance regulator protein) gene [2]. Although $\mathrm{CF}$ is a multiorgan disease, morbidity and mortality result mainly from progressive pulmonary disease [3]. The lung involvement in $\mathrm{CF}$ is characterized by an excessive neutrophilic inflammation in the airways associated with inflammatory markers, e.g. high levels of IL-8, elevated neutrophil elastase (NE) activity [4], and increased oxidative damage [5]. Past studies found that CFTR not only regulates the efflux of chloride but also of other organic anions such as glutathione (GSH) [6]. Previous data report that GSH

\section{KARGER}

Fax +41613061234 E-Mail karger@karger.ch www.karger.com
(C) 2009 S. Karger AG, Basel

0025-7931/10/0805-0393\$26.00/0

Accessible online at:

www.karger.com/res
Matthias Griese

Cystic Fibrosis Center, Children's Hospital, University of Munich

Lindwurmstrasse 4, DE-80337 Munich (Germany)

Tel. +49895160 7871, Fax +498951607872

E-Mail matthias.griese@med.uni-muenchen.de 
concentrations are low in epithelial lining fluid of CF patients [7, 8]. Elevation of GSH levels in type II alveolar epithelial cells downregulated the proinflammatory cytokines IL-1 $\beta$, IL- 8 and tumor necrosis factor- $\alpha$ [9]. In clinical studies elevation of GSH levels by oral administration of the GSH prodrug $\mathrm{N}$-acetylcysteine in CF patients over 4 weeks decreased levels of IL- 8 in induced sputum samples [10] and a 2-week inhalation of GSH in CF patients decreased levels of the proinflammatory mediator $\mathrm{PGE}_{2}$ [11], while GSH depletion was associated with elevated oxidative stress-mediated proinflammatory signaling [12]. Further studies suggest that GSH downregulates inflammatory response by inhibiting transcription factors such as NF- $\mathrm{KB}$ or AP-1 $[13,14]$. Thus, in addition to its antioxidant property $\mathrm{GSH}$ plays a key role in immune responses [14].

In the past years, induced sputum samples are increasingly used, as they are a useful and minimal invasive tool to monitor pulmonary diseases [15-22]. Because of the high viscosity induced sputum samples of CF patients need to be dispersed before analysis. Among several methods evaluated, the method utilizing dithiothreitol (DTT) is widely used because of its ability to split disulfide bonds and disperse sputum samples [15]. However, due to its reducing and denaturing effect DTT has been shown to preanalytically affect levels of various mediators [23-28] and it is most likely that DTT also influences oxidant-dependent variables like GSH.

Several studies have assessed GSH levels in induced sputum samples of patients with various pulmonary diseases including CF [29], asthma [25, 30], and COPD [31, 32] without the use of DTT for sample processing. Though one study demonstrated an effect of DTT on the assay used for GSH measurements [30], none of these studies systematically compared methods with and without the use of DTT to assess changes in intra- and extracellular GSH levels and to analyze the impact on other relevant cellular parameters.

Our laboratory established a mechanical method without the use of DTT (hereinafter referred to as 'D-PBS method') for sputum processing to investigate oxidative state and inflammation in CF-induced sputum samples. Here we compared the new method with the conventional DTT method and the results show equivalence for basal cellular variables and superiority for extracellular and intracellular GSH measurements, which are artificially elevated by the DTT method. These results are clinically relevant and very important for the increasing number of studies analyzing airway inflammation in CF patients via sputum induction.

\section{Material and Methods}

\section{Study Design}

The study was approved by the institutional review board of the University of Munich and informed consent from all CF subjects was obtained prior to the study. Induced sputum samples from $10 \mathrm{CF}$ patients were used in this study. Following the application of $200 \mu \mathrm{g}$ of the $\beta_{2}$-sympathomimetic salbutamol, subjects inhaled hypertonic saline solution (5.85\%) for 15 min using a Pari Boy SX combined with an LC Sprint jet nebulizer (Pari, Munich, Germany). To avoid contamination, saliva was expectorated into a separate container. Patients were encouraged to produce sputum samples at 5-min intervals. The first portion was used for microbiological analyses. Subsequent portions were transported to the laboratories on ice. Plugs were selected with forceps and the sample was divided into two approximately equal aliquots and processed within $30 \mathrm{~min}$ side by side in two ways. One aliquot was homogenized with 4 times the volume of D-PBS and 5 times the volume of $10 \%$ DTT (Calbiochem, Darmstadt, Germany) in a shaking water bath with $37^{\circ} \mathrm{C}$ for $15 \mathrm{~min}$ as routinely used and previously described [33]. The other aliquot was divided with two sterile blunt forceps into small portions of approximately $0.2 \mathrm{~g}$ and 9 times the volume of D-PBS was added. Samples were homogenized by gentle passage repeated 20 times through an 18 gauge needle. For some experiments, a further aliquot was divided and homogenized with 4 times the volume of D-PBS and 5 times the volume of $10 \%$ DTT on ice for $15 \mathrm{~min}$.

The following steps were carried out in parallel for both methods. Homogenized samples were consecutively filtered through a 100 - and $40-\mu \mathrm{m}$ cell strainer and centrifuged at $300 \mathrm{~g}$ and $4^{\circ} \mathrm{C}$ for $10 \mathrm{~min}$.

The supernatant was carefully transferred into other vials and centrifuged again at $10,000 \mathrm{~g}$ and $4^{\circ} \mathrm{C}$ for $5 \mathrm{~min}$. The supernatant was pooled and divided into Eppendorf cups. One part was immediately frozen at $-80^{\circ} \mathrm{C}$ until analysis. The other part was used for determination of thiols. To assess free GSH levels, samples were precipitated with trichloroacetate (Sigma-Aldrich, Munich, Germany) and centrifuged at $1,500 \mathrm{~g}$ and $4^{\circ} \mathrm{C}$ for $5 \mathrm{~min}$. The supernatant was frozen immediately at $-80^{\circ} \mathrm{C}$ until analysis. To measure total GSH levels, tributylphosphine (Sigma-Aldrich) buffer was added, and samples were incubated for $30 \mathrm{~min}$ at $4^{\circ} \mathrm{C}$. Then the samples were precipitated and centrifuged at $1,500 \mathrm{~g}$ and $4^{\circ} \mathrm{C}$ for $5 \mathrm{~min}$. The supernatant was frozen immediately at $-80^{\circ} \mathrm{C}$ until analysis.

Cell suspension was resuspended with D-PBS, total cell count was determined in a Neubauer chamber and cell viability was assessed with the trypan blue exclusion method. Cytospin slides for differential cell counts with 30,000 cells per slide were prepared, fixed and stained according to May-Grünwald-Giemsa. The remaining cell suspension was diluted to $10^{6} \mathrm{cells} / \mathrm{ml}$ and was used for FACS analysis.

Measurement of GSH Levels in Sputum Supernatant

Thawed samples were derivatized with 7-fluorobenzofurazan-4-sulfonic acid ammonium salt (SBD-F; Fluka, Munich, Germany) in boric acid (Merck, Darmstadt, Germany) buffer and were incubated at $60^{\circ} \mathrm{C}$ for $1 \mathrm{~h}$ as described previously [34]. Samples were stored at $4^{\circ} \mathrm{C}$ until analyzed by means of reversed-phase HPLC (RP-HPLC) within $24 \mathrm{~h}$. Kuhn et al. [34] gave a detailed description of the running conditions. Standard measurements 
Table 1. Comparison of methods of processing sputum samples

\begin{tabular}{lll}
\hline & \multicolumn{2}{l}{ Methods } \\
\cline { 2 - 3 } & D-PBS & DTT \\
\hline Used weight, g & $0.70(0.35-0.86)$ & $0.71(0.3-0.93)$ \\
$\begin{array}{l}\text { Total cell count } \\
10^{6} \text { cells/ml }\end{array}$ & $6.47(2.15-10.76)$ & $6.51(3.06-11.56)$ \\
Differential cell counts, \% & \\
$\quad$ Neutrophils & $96.89(92.5-99.3)$ & $97.06(87.5-99.7)$ \\
Eosinophils & $0.26(0.0-2.3)$ & $0.21(0.0-1.8)$ \\
Basophils & $0.19(0.0-1.0)$ & $0.31(0.0-1.5)$ \\
$\quad$ Macrophages & $0.94(0.0-2.0)$ & $1.18(0.0-6.0)$ \\
Lymphocytes & $1.35(0.0-4.5)$ & $1.18(0.0-5.0)$ \\
Cell viability, \% & $83.7(77-92)$ & $83.5(72-88)$ \\
\hline
\end{tabular}

All data are given as means (with the range in parentheses) from 10 different subjects. No significant differences were found for investigated variables.

were performed after analysis of ten samples. All runs were performed in duplicate. If deviation of duplicates was greater than $5 \%$ a third run was carried out. The mean deviation of the duplicates was $3.2 \%$ within a range of $0.2-7.1 \%$. GSH concentrations were calculated with respect to GSH standard measurements which were carried out after every tenth sample. Intra-assay and interassay variability of the GSH standards were tested by linear regression $\left(r^{2}=0.997\right.$ and $r^{2}=0.97$, respectively). In previous tests recovery experiments were performed by spiking and the mean recovery rate was $94 \%$ within a range of $87.6-99.6 \%$.

\section{FACS Analyses}

Monoclonal fluorochrome-labeled antibodies were purchased from BD Pharmingen (Heidelberg, Germany) unless otherwise specified. Markers of interests were CD63, CXCR1, CD11b, CD15s, Cam5.2, CD3 and CD4. To assess intracellular respiratory burst we used the dihydrorhodamine (DHR) 123 (AnaSpec/ MoBiTec, Göttingen, Germany) method [29]. Intracellular GSH levels were measured with monochlorobimane (Fluka) [10, 35]. Samples were measured with an FACSCalibur (Becton Dickinson, Heidelberg, Germany) and an FACS Canto II (Becton Dickinson). Results were analyzed with Cell Quest software version 1.3 (Becton Dickinson) and BD FACS Diva (Becton Dickinson) software, respectively. The results are given in mean fluorescence intensity. We used annexin $\mathrm{V}$ and propidium iodide to exclude apoptotic (annexin $\mathrm{V}+$ /propidium iodide-) and necrotic (annexin $\mathrm{V}+$ /propidium iodide + ) cells from analysis as well as isotype controls to exclude nonspecific bindings. For DHR, monochlorobimane, annexin $\mathrm{V}$, and propidium iodide negative controls were applied.

\section{Measurement of NE}

NE was analyzed in sputum supernatant by a chromogenic spectrophotometric assay as described elsewhere [36].

Method for Cystic Fibrosis Sputum

Processing
Statistical Analysis

Agreement between the two methods was analyzed by the Bland-Altman method [37]. The difference of the two methods (bias) is analyzed as a function of the mean of the two measurements of each sample. If the two methods produce the same result, the average of the bias will be close to zero. Agreement was considered to be acceptable if differences of means were approximately $5 \%$ or less.

Means and standard error of means or ranges are given for each variable. The sputum processing protocols were compared for differences with the nonparametric Wilcoxon-signed rank test for paired values. $\mathrm{p}<0.05$ was considered statistically significant.

\section{Results}

\section{Patient Characteristics}

Ten patients with CF were included in this study, 4 of whom were males (mean age 31.1 years, ranging from 22 to 41 years). Nine patients were infected with Pseudomonas aeruginosa. Mean $\mathrm{FEV}_{1}$ (\% of predicted) was $54.8 \%$ (range: $24.8-87.4 \%$ ). All patients were stable and none had pulmonary exacerbations as defined by Fuchs et al. [38] within the preceding 4 weeks. No adverse events, i.e. bronchoconstriction, occurred due to the induced sputum procedure.

\section{Cell Count and Cell Viability}

The amount of sputum obtained was sufficient in all subjects and the average weight was $1.6 \mathrm{~g}$ (range: $0.679-$ $2.23 \mathrm{~g}$ ). There was no statistically significant difference for total cell count, differential cell count, and cell viability for the D-PBS and DTT method (table 1). Agreement of the two methods was high for neutrophils, but relatively low for other cellular subpopulations (table 2).

\section{Neutrophil Markers}

In the set of neutrophil surface markers used in this study and respiratory burst in neutrophils no significant difference was found for both methods (fig. 1). The agreement of the two methods was acceptable for CD63, CD11b, and DHR123, whereas it was relatively low for CXCR1 (table 2). NE levels in samples treated with DTT were comparable to those treated with PBS and the agreement of the two methods was good (fig. 2; table 2).

\section{Intracellular GSH Levels}

Cell type-specific intracellular levels of GSH were analyzed by flow cytometry. All samples were sufficient for measurement of neutrophils and epithelial cells. In neutrophils and epithelial cells intracellular GSH levels were significantly higher in DTT-treated samples compared to 


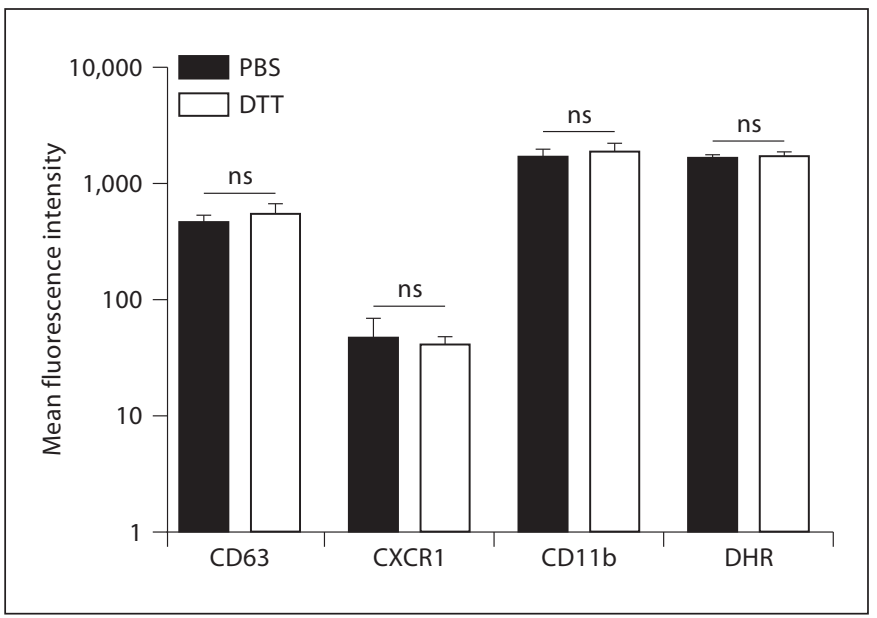

Fig. 1. FACS analysis of neutrophil markers and respiratory burst. Mean fluorescence intensity of CD63, CXCR1, CD11b, and DHR on neutrophilic granulocytes in IS samples processed with either D-PBS or DTT $(n=10)$ is shown. CD63 is a specific marker for intracellular primary granules containing active substances like myeloperoxidase and NE and is expressed on the surface by fusion of the granules with the cell membrane [10]. CXCR1 is a wellknown receptor for the proinflammatory chemokine IL-8, which is abundant in airway fluids of CF patients. CD11b is expressed on neutrophils after diapedesis into the airways and is also thought to play a role in the phagocytosis activity of neutrophils [4]. None of the markers differed significantly between the two processing methods. Agreement was good for CD63 and DHR and acceptable for CD11b, whereas for CXCR1 it was poor.

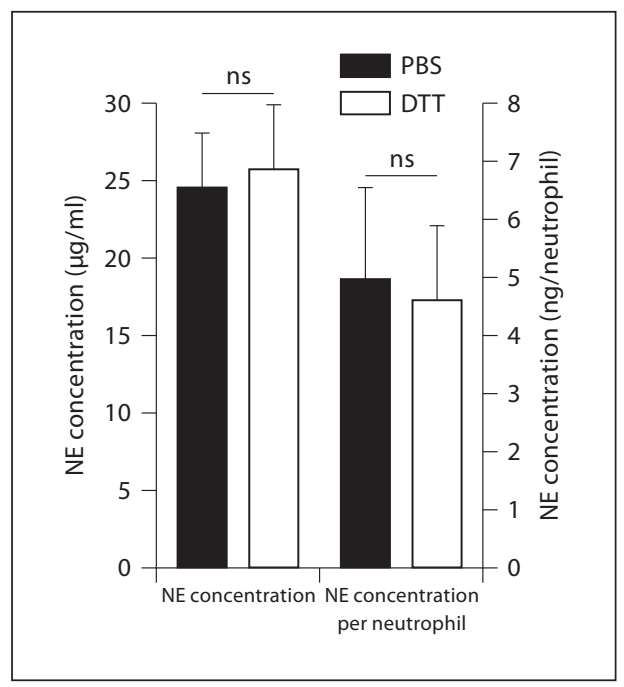

Fig. 2. NE levels. NE concentrations (left y-axis) in sputum supernatant and NE concentrations normalized to neutrophil counts (right y-axis) are given. There was no significant difference between the two methods. In one sample pair NE was not detectable $(\mathrm{n}=10)$.
Table 2. Bland-Altman agreement of methods of processing sputum samples

Bias, \% difference of the two methods compared

$\begin{array}{lc}\text { Basal cellular parameters } & \\ \text { Total cell count } & 5.5 \pm 5.5 \\ \text { Cell viability } & -0.9 \pm 1.6 \\ \text { Differential cell count } & \\ \quad \text { Neutrophils } & 0.1 \pm 0.7 \\ \quad \text { Basophils } & -12.2 \pm 12.2 \\ \quad \text { Eosinophils } & 29.5 \pm 66.6 \\ \quad \text { Lymphocytes } & -21.4 \pm 38.8 \\ \quad \text { Monocytes } & -41.4 \pm 25.2\end{array}$

\section{Neutrophil elastase}

Concentration in supernatant $\quad 2.3 \pm 4.6$

Concentration per neutrophil $\quad-3.6 \pm 7.0$

Neutrophil markers in flow cytometry

CD63

$-0.6 \pm 13.9$

CXCR1

$34.7 \pm 32.3$

CD11b

$7.3 \pm 5.5$

DHR

$-0.9 \pm 7.1$

\section{Intracellular GSH levels}

Neutrophils

Lymphocytes

$138.3 \pm 14.5$

Epithelial cells

$150.3 \pm 16.7$

$86.9 \pm 15.0$

Extracellular GSH levels

Free GSH

$105.9 \pm 7.2$

Total GSH

$4.7 \pm 5.1$

Ratio free/total GSH

Summary of the comparison according to Bland-Altman of the two methods is given, i.e. the novel mechanical sputum processing method and the conventional DTT method. For easy comparison the \% of bias and their standard error of mean are given. A total of 10 pairs were analyzed except for intracellular GSH levels in lymphocytes, where only in 5 sample pairs the numbers of events were appropriate to perform FACS analysis.

D-PBS-treated samples $(\mathrm{p}=0.002)$. In line with these data, the agreement between the two methods was not acceptable, suggesting that the thiol-independent method of sample preparation should be used if intracellular GSH is assessed (table 2). In lymphocytes the number of events detected was too low in 3 samples to assess the DPBS method and in 4 samples to assess the DTT method. These samples were not included in the analyses and the numbers were too low to reach the significance level set before (fig. 3).

Independent of the processing method, intracellular GSH levels were lower in neutrophils than in lympho- 


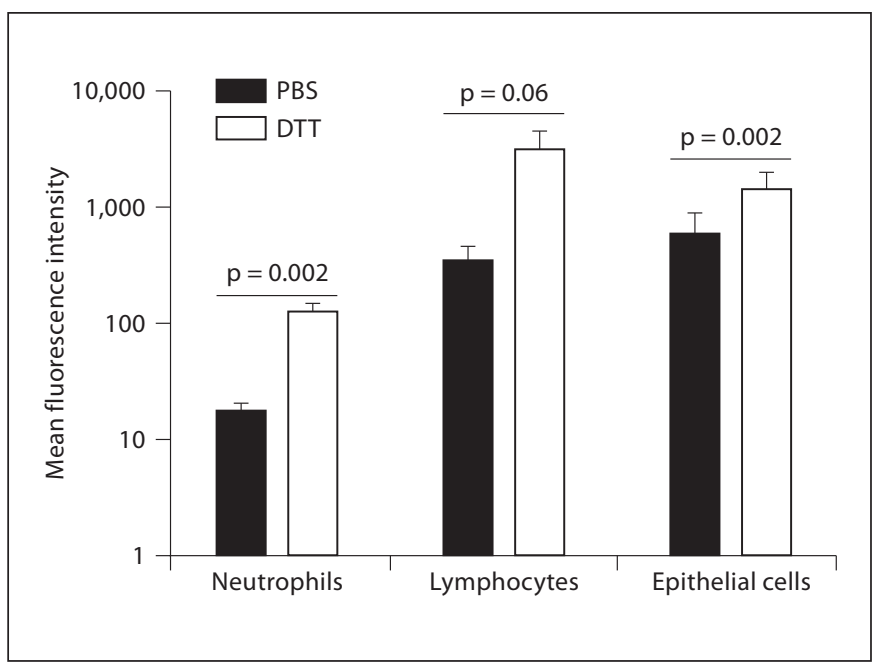

Fig. 3. Intracellular GSH levels. Comparison of GSH levels intracellularly assessed by FACS is shown. Intracellular GSH levels in samples processed with the DTT method were significantly higher in neutrophil granulocytes and epithelial cells $(\mathrm{p}=0.002 ; \mathrm{n}=$ 10). In lymphocytes, counted events in 3 samples processed with D-PBS and 5 samples processed with DTT were too low and were taken out of analysis. Statistically, there was only a tendency of higher intracellular GSH levels in lymphocytes in DTT samples compared to D-PBS samples $(\mathrm{p}=0.06)$. Cam5.2 is a pan-epithelial marker [46], CD15s is expressed on granulocytes, while CD3 and CD4 are well-known markers for T cells. These markers were used for classification of the cell populations.

cytes and epithelial cells $(\mathrm{p}<0.05$ and $\mathrm{p}=0.002$, respectively). The latter two cell types had comparable intracellular GSH levels (fig. 3).

\section{Assessment of Extracellular GSH by RP-HPLC}

Extracellular free GSH levels were significantly higher in samples treated with DTT compared to those processed with D-PBS ( $p=0.002)$. The levels of free GSH in samples treated with DTT were comparable with total GSH levels in samples treated with both methods. Mean ratio of free/total GSH was 31\% (range: $15.8-41.5 \%$ ) and 95.6\% (range: 82.7-108.6\%) in samples treated with DPBS and DTT, respectively (fig. 4). In concordance with these results, the agreement of the two methods was poor (table 2), clearly showing an about $100 \%$ significant increase in free extracellular GSH and intracellular GSH (see above) after treatment with DTT. As expected, total GSH measured after complete reduction of the sample, which leads to availability of all thiol groups in the samples, showed comparable levels and good agreement of the two methods (table 2).

Method for Cystic Fibrosis Sputum Processing

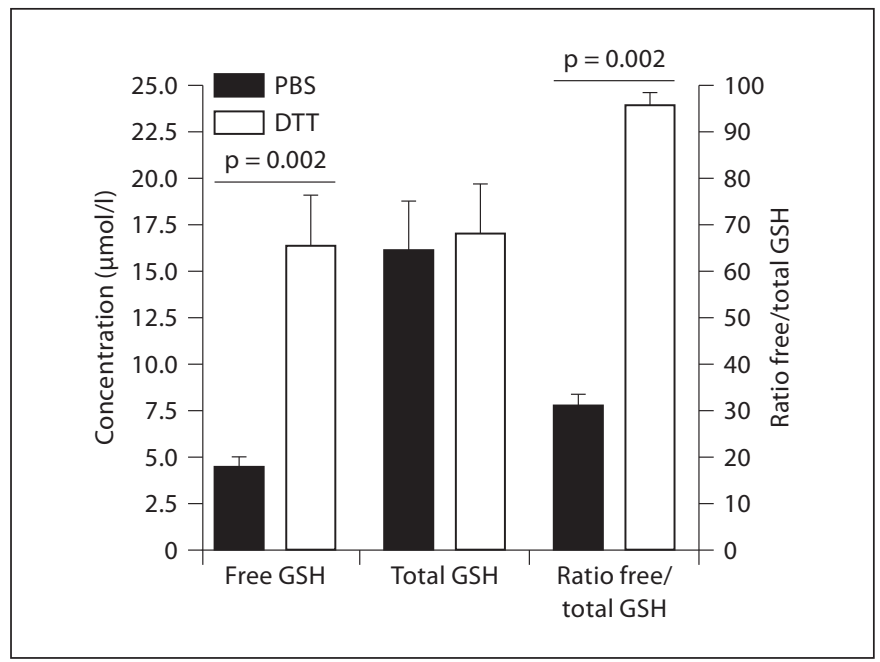

Fig. 4. Extracellular GSH levels. Extracellular levels for free and total GSH (left y-axis) and the ratio of free/total GSH (right y-axis) measured in induced sputum supernatant by RP-HPLC are given. Free GSH levels and the ratio of free/total GSH were significantly higher with the DTT method compared to the D-PBS method $(\mathrm{p}=0.002 ; \mathrm{n}=10)$.

\section{There Are No Temperature-Driven Effects on Determination of GSH}

To exclude temperature-driven effects of DTT on GSH measurements, 4 induced sputum samples of CF patients were processed as mentioned above (1) by the presented method using D-PBS, (2) with DTT at $37^{\circ} \mathrm{C}$, and (3) additionally with DTT on ice. The effect of DTT on GSH measurements was similar for both temperature conditions. These results indicate that the determination of GSH was not dependent on the temperature at which the preparation of sputum was done in the presence of DTT. Thus, elevated GSH levels were due to the addition of DTT (for all online supplementary data, see www. karger.com/doi/10.1159/000271607.

\section{Discussion}

Induced sputum is the most commonly used noninvasive method to analyze airway inflammation in CF patients ex vivo, but owing to the complex matrix of the sample material, precise and reliable analysis of sputum constituents depends critically on preanalytical issues. Here, we systematically compared the conventional method used for sputum processing by DTT with a novel method developed in our laboratories and demonstrat- 
ed that the presented sputum processing method is superior to the conventional DTT method, in particular for measuring redox-dependent parameters, such as GSH, in sputum samples. These results are novel and clinically relevant for the increasing number of studies analyzing airway inflammation in CF patients via sputum induction.

DTT is a strong reductant which disrupts the sputum matrix that is stabilized by disulfide bonds and thus allows the liberation and analysis of cells and solutes. However, several studies pointed out effects of DTT on various markers [23, 25-28]. In this study we systematically analyzed the effects of the standard DTT sputum processing method on various cellular variables as well as on extra- and intracellular GSH levels in comparison to a novel method using mechanical disruption of very small aliquots of the samples. Viability, number of total cells recovered and cell differential were not significantly different between the two methods. The Bland-Altman analysis revealed that the agreement between the DTT method and the mechanical method was appropriate for total cell count, cell viability and differential cell count for neutrophils while it was low for differentials of other cell types. This was most likely due to the small numbers of the other cell types in investigated induced sputum samples (tables 1,2). However, free extracellular and intracellular GSH levels were significantly higher in samples treated with DTT. Agreement analyses also revealed significant differences in extracellular and intracellular GSH measurements except for measurements of extracellular total GSH (table 2). This result may be expected because of the reducing capacity of DTT in releasing GSH from disulfide bonds in the same manner as tributylphosphine which we used to detect total GSH levels in our method. This altering effect of DTT was already shown in a previous study for extracellular GSH concentrations in induced sputum samples of patients with asthma [25], but to the authors' knowledge an alteration of intracellular GSH levels, i.e. the intracellular redox potential, has not been shown until now.

The alteration of GSH levels by DTT shown in this study could also be due to interference of DTT with the method for GSH measurements. Previous studies have shown significant effects of DTT on GSH measurements by a spectrophotometric method using the reagent DTNB which was - at least in part - due to the reduction of DTNB itself by DTT $[25,29,30]$. As for the RP-HPLC method we used for the present study, Kuhn et al. [34] previously reported that the reaction of DTT and SBD-F yields fluorescent by-products. To exclude possible inter- ference, blanks with or without the addition of DTT were analyzed. Latter measurements revealed unspecific peaks after retention times of approximately 6.5-6.8 and 7.8$8.5 \mathrm{~min}$ in the presence of DTT. As the peak for GSH appears at approximately $8.6-8.9 \mathrm{~min}$, the by-products should not or only minimally interfere with our GSH measurements (online suppl. data). This is also supported by our results on total GSH levels which were comparable with samples processed with and without DTT, indicating that there was no significant interference of DTT with the RP-HPLC assay we used in this study (fig. 4). Additionally, monochlorobimane - which was used for detection of intracellular GSH in the present study - is a nonfluorescent probe which is able to permeate living cells and specifically links to GSH via glutathione-S-transferase resulting in the fluorescent adduct glutathione-S-bimane [10]. The specificity of the intracellular enzyme system makes it unlikely that other DTT by-products are detected by this method. The results we obtained with the RP-HPLC method and with the flow cytometry method with monochlorobimane were consistent. Taken together, our results indicate that higher levels of GSH in DTTtreated samples result from the ability of DTT to break up disulfide bonds of protein disulfide (RS-SG).

In a previous comparative study using DTT or D-PBS for the preparation of sputum samples from patients with asthma, cell viability was higher with the D-PBS method while total cell count was higher when samples were processed with DTT [15]. The use of an optical isomer of DTT, dithioerythritol, also yielded a higher recovery of total cells compared to D-PBS [23]. However, in our study there was no significant difference and agreement was acceptable between the two methods regarding the means of cell count, cell differential and cell viability. The critical step responsible for the improved recovery by our method was the homogenization step. In pilot experiments we found that it is critical to divide the sputum aliquots into further small portions not larger than approximately 0.2 $\mathrm{g}$ and to homogenize these by gentle aspiration and dispersion in a 9-fold volume of D-PBS. Such a procedure was omitted in earlier studies. Previously, the authors treated the samples with PBS without any further homogenizing step [15]. Louis et al. [23] reported that sputum samples were agitated for $10 \mathrm{~s}$ and rocked for a further $30 \mathrm{~min}$ for either method. In case only PBS is used it is questionable whether this is enough to disperse cells in highly viscous sputum samples like those of CF patients.

The effect of DTT on the measurement of NE levels was tested in studies with a cohort of patients with CF [39] and chronic obstructive pulmonary disease [40]. No signifi- 
cant changes were reported, which is in accordance with our findings. NE levels and levels normalized to neutrophil numbers in supernatant as assessed by Bland-Altman analysis were comparable for both methods (table 2).

As for the effect of DTT on surface markers and respiratory burst in neutrophils as assessed by flow cytometry in this study, to the authors' knowledge there have so far been no comparative studies. However, in this study DTT had no effect on CD63 and DHR, but a small effect on CD11b and a significant effect on CXCR1 measurements when compared to the D-PBS method. A possible explanation for the increased CXCR1 expression found on the neutrophil surface after DTT treatment could be the higher accessibility of anti-CXCR1 antibodies to the binding site. Within CXCR1, an extracellular disulfide bond exists between the N-terminus and the first extracellular loop [41]. DTT could break down this disulfide bond and change the conformation and antibody accessibility of the receptor.

In a previous study, our laboratory showed that DTT had no effect on measurements of the cytokines IL-1 $\beta$ and tumor necrosis factor- $\alpha$, the leukotriene $\mathrm{LTB}_{4}$, and the chemokine IL-8 in sputum samples from patients with CF (online suppl. data) [42]. Similarly, other studies did not find altered levels of IL-8 in sputum samples treated with either DTT or dithioerythritol compared to PBS in patients with asthma $[15,23]$. In contrast, other studies did find DTT-dependent changes in measured levels of IL-8 as assessed by ELISA [40, 43] and in a range of cytokines and chemokines as analyzed by a multiplex bead array immunoanalysis [26]. However, in an extensive review of Kelly et al. [28] most of these markers were shown to be unaffected by DTT. Neverthelss, the ratio of the redox pair GSH/GSH disulfide (GSSG) is known to play an important role in the activation of the proinflammatory transcription factor NF- $\mathrm{B}$ [44]. Elevation of intracellular GSH levels and GSH/GSSG ratio resulted in the inhibition of NF- $\kappa$ B activation [45]. Although it seems unlikely that the short incubation time (i.e. $15 \mathrm{~min}$ ) of sputum samples with DTT exerts effects on the NF- $\mathrm{B}$ driven inflammatory response, to the authors' knowledge short-term effects of DTT on inflammatory pathways have never been investigated until now.

\section{Conclusions}

We developed a novel mechanical method processing many small portions of induced sputum samples. We show that this method is equivalent to the commonly used DTT method for measurement of many cellular and fluid phase variables in sputum samples. Additionally, the D-PBS method - in contrast to the DTT method does not affect redox-dependent variables such as GSH. These results are novel and clinically relevant for the increasing number of studies analyzing airway inflammation in CF patients via induced sputum.

\section{Acknowledgements}

The authors would like to thank S. Franke for excellent technical assistance in performing RP-HPLC analysis for measurement of GSH levels in sputum supernatant. Thanks also go to A. Angerer, R. Koplin (Children's Hospital, University of Munich) and to R. Fischer (Department of Internal Medicine, University of Munich) for providing us with induced sputum samples from patients with CF.

This study was supported by grants of CF Foundation Therapeutics, Inc., USA and the Mukoviszidose e.V., Germany to M.G.

\section{References}

1 Dodge JA: Why screen for cystic fibrosis? A clinician's view. Acta Paediatr Suppl 1999;88: 28-32.

2 Rommens JM, Iannuzzi MC, Kerem B, Drumm ML, Melmer G, Dean M, Rozmahel R, Cole JL, Kennedy D, Hidaka N: Identification of the cystic fibrosis gene: chromosome walking and jumping. Science 1989;245: 1059-1065

3 Suri R, Metcalfe C, Lees B, Grieve R, Flather M, Normand C, Thompson S, Bush A, Wallis C: Comparison of hypertonic saline and alternate-day or daily recombinant human deoxyribonuclease in children with cystic fibrosis: a randomised trial. Lancet 2001;358: 1316-1321.
4 Sagel SD: Noninvasive biomarkers of airway inflammation in cystic fibrosis. Curr Opin Pulm Med 2003;9:516-521.

5 Brown RK, Kelly FJ: Evidence for increased oxidative damage in patients with cystic fibrosis. Pediatr Res 1994;36:487-493.

6 Linsdell P, Hanrahan JW: Glutathione permeability of CFTR. Am J Physiol 1998;275: C323-C326.

7 Roum JH, Buhl R, McElvaney NG, Borok Z, Crystal RG: Systemic deficiency of glutathione in cystic fibrosis. J Appl Physiol 1993;75: 2419-2424.

8 Griese M, Ramakers J, Krasselt A, Starosta V, Van Koningsbruggen S, Fischer R, Ratjen F, Mullinger B, Huber RM, Maier K, Rietschel
E, Scheuch G: Improvement of alveolar glutathione and lung function but not oxidative state in cystic fibrosis. Am J Respir Crit Care Med 2004;169:822-828.

9 Haddad JJ, Safieh-Garabedian B, Saade NE, Land SC: Thiol regulation of pro-inflammatory cytokines reveals a novel immunopharmacological potential of glutathione in the alveolar epithelium. J Pharmacol Exp Ther 2001;296:996-1005.

10 Tirouvanziam R, Conrad CK, Bottiglieri T, Herzenberg LA, Moss RB, Herzenberg LA: High-dose oral N-acetylcysteine, a glutathione prodrug, modulates inflammation in cystic fibrosis. Proc Natl Acad Sci USA 2006; 103:4628-4633. 
11 Hartl D, Starosta V, Maier K, Beck-Speier I, Rebhan C, Becker BF, Latzin P, Fischer R, Ratjen F, Huber RM, Rietschel E, KraussEtschmann S, Griese M: Inhaled glutathione decreases PGE2 and increases lymphocytes in cystic fibrosis lungs. Free Radic Biol Med 2005;39:463-472.

12 Haddad JJ: Glutathione depletion is associated with augmenting a proinflammatory signal: evidence for an antioxidant/pro-oxidant mechanism regulating cytokines in the alveolar epithelium. Cytokines Cell Mol Ther 2000;6:177-187.

13 Rahman I, MacNee W: Oxidative stress and adaptive response of glutathione in bronchial epithelial cells. Clin Exp Allergy 2002;32: 486-488.

14 Hudson VM: Rethinking cystic fibrosis pathology: the critical role of abnormal reduced glutathione (GSH) transport caused by CFTR mutation. Free Radic Biol Med 2001;30:1440-1461.

15 Efthimiadis A, Pizzichini MM, Pizzichini E, Dolovich J, Hargreave FE: Induced sputum cell and fluid-phase indices of inflammation: comparison of treatment with dithiothreitol versus phosphate-buffered saline. Eur Respir J 1997;10:1336-1340.

16 Bartoli ML, Di Franco A, Vagaggini B, Bacci E, Cianchetti S, Dente FL, Tonelli M, Paggiaro PL: Biological markers in induced sputum of patients with different phenotypes of chronic airway obstruction. Respiration 2009;77:265-272

17 Zeng M, Wen Y, Liu LY, Wang H, Guan KP, Huang X: Role of TNF-alpha, STNF-R55 and STNF-R75 in inflammation of acute exacerbations of chronic obstructive pulmonary disease. Respiration 2009;78:399-403.

18 Aitken ML, Greene KE, Tonelli MR, Burns JL, Emerson JC, Goss CH, Gibson RL: Analysis of sequential aliquots of hypertonic saline solution-induced sputum from clinically stable patients with cystic fibrosis. Chest 2003;123:792-799.

19 Economidou F, Samara KD, Antoniou KM, Siafakas NM: Induced sputum in interstitial lung diseases: novel insights in the diagnosis, evaluation and research. Respiration 2009; 77:351-358.

20 Mazur W, Stark H, Sovijarvi A, Myllarniemi M, Kinnula VL: Comparison of 8-isoprostane and interleukin-8 in induced sputum and exhaled breath condensate from asymptomatic and symptomatic smokers. Respiration 2009;78:209-216.

21 Henig NR, Tonelli MR, Pier MV, Burns JL, Aitken ML: Sputum induction as a research tool for sampling the airways of subjects with cystic fibrosis. Thorax 2001;56:306311.
22 Damjanov N, Ostojic P, Kaloudi O, Alari S, Guiducci S, Stanflin N, Nestorovic B, Knezevic J, Camiciottoli G, Porta F, Pistolesi M, Ibba-Manneschi L, Conforti ML, Candelieri A, Matucci Cerinic M: Induced sputum in systemic sclerosis interstitial lung disease: comparison to healthy controls and bronchoalveolar lavage. Respiration 2009;78:5662.

23 Louis R, Shute J, Goldring K, Perks B, Lau LC, Radermecker M, Djukanovic R: The effect of processing on inflammatory markers in induced sputum. Eur Respir J 1999;13: 660-667.

24 Wang F, He B: The effect of dithiothreitol on chemotactic factors in induced sputum of chronic obstructive pulmonary disease patients. Respiration 2009;78:217-222.

25 Beier J, Beeh KM, Kornmann O, Buhl R: Induced sputum methodology: validity and reproducibility of total glutathione measurement in supernatant of healthy and asthmatic individuals. J Lab Clin Med 2004;144:3844

26 Erin EM, Jenkins GR, Kon OM, Zacharasiewicz AS, Nicholson GC, Neighbour H, Tennant RC, Tan AJ, Leaker BR, Bush A, Jose PJ, Barnes PJ, Hansel TT: Optimized dialysis and protease inhibition of sputum dithiothreitol supernatants. Am J Respir Crit Care Med 2008;177:132-141.

27 Woolhouse IS, Bayley DL, Stockley RA: Effect of sputum processing with dithiothreitol on the detection of inflammatory mediators in chronic bronchitis and bronchiectasis. Thorax 2002;57:667-671.

28 Kelly MM, Keatings V, Leigh R, Peterson C, Shute J, Venge P, Djukanovic R: Analysis of fluid-phase mediators. Eur Respir J 2002; 20(suppl 37):24s-39s.

29 Dauletbaev N, Rickmann J, Viel K, Diegel H, von Mallinckrodt C, Stein J, Wagner TO, Bargon J: Antioxidant properties of cystic fibrosis sputum. Am J Physiol Lung Cell Mol Physiol 2005;288:L903-L909.

30 Dauletbaev N, Rickmann J, Viel K, Buhl R, Wagner TO, Bargon J: Glutathione in induced sputum of healthy individuals and patients with asthma. Thorax 2001;56:13-18.

31 Beeh KM, Beier J, Koppenhoefer N, Buhl R: Increased glutathione disulfide and nitrosothiols in sputum supernatant of patients with stable COPD. Chest 2004;126:11161122 .

32 Beier J, Beeh KM, Kornmann O, Buhl R: Stability of glutathione in induced sputum: impact of freezing. Respiration 2003;70:523527.

33 Hilliard JB: Standard Operating Procedures on Sputum Processing - Therapeutics Development Network Coordinating Center (TDN-CC), 2003.

34 Kuhn KS, Krasselt AI, Furst P: Glutathione and glutathione metabolites in small tissue samples and mucosal biopsies. Clin Chem 2000;46:1003-1005
35 Kamencic H, Lyon A, Paterson PG, Juurlink $\mathrm{BH}$ : Monochlorobimane fluorometric method to measure tissue glutathione. Anal Biochem 2000;286:35-37.

36 Hilliard JB, Konstan MW, Davis PB: Inflammatory mediators in CF patients. Methods Mol Med 2002;70:409-431.

37 Bland JM, Altman DG: Statistical methods for assessing agreement between two methods of clinical measurement. Lancet 1986;1: 307-310.

38 Fuchs HJ, Borowitz DS, Christiansen DH, Morris EM, Nash ML, Ramsey BW, Rosenstein BJ, Smith AL, Wohl ME: Effect of aerosolized recombinant human DNase on exacerbations of respiratory symptoms and on pulmonary function in patients with cystic fibrosis. The Pulmozyme Study Group. N Engl J Med 1994;331:637-642.

39 Liu H, Lazarus SC, Caughey GH, Fahy JV: Neutrophil elastase and elastase-rich cystic fibrosis sputum degranulate human eosinophils in vitro. Am J Physiol 1999;276:L28L34

40 Culpitt SV, Maziak W, Loukidis S, Nightingale JA, Matthews JL, Barnes PJ: Effect of high dose inhaled steroid on cells, cytokines, and proteases in induced sputum in chronic obstructive pulmonary disease. Am J Respir Crit Care Med 1999;160:1635-1639.

41 Holmes WE, Lee J, Kuang WJ, Rice GC, Wood WI: Structure and functional expression of a human interleukin-8 receptor. Science 1991;253:1278-1280.

42 Griese M, Latzin P, Kappler M, Weckerle K, Heinzlmaier T, Bernhardt T, Hartl D: Alpha1-antitrypsin inhalation reduces airway inflammation in cystic fibrosis patients. Eur Respir J 2007;29:240-250.

43 Kim JS, Hackley GH, Okamoto K, Rubin BK: Sputum processing for evaluation of inflammatory mediators. Pediatr Pulmonol 2001; 32:152-158.

44 Pineda-Molina E, Klatt P, Vazquez J, Marina A, Garcia de Lacoba M, Perez-Sala D, Lamas S: Glutathionylation of the P50 subunit of NF-kappaB: a mechanism for redox-induced inhibition of DNA binding. Biochemistry 2001;40:14134-14142.

45 Rahman I, Mulier B, Gilmour PS, Watchorn T, Donaldson K, Jeffery PK, MacNee W: Oxidant-mediated lung epithelial cell tolerance: the role of intracellular glutathione and nuclear factor-kappaB. Biochem Pharmacol 2001;62:787-794.

46 Kraemer PS, Sanchez CA, Goodman GE, Jett J, Rabinovitch PS, Reid BJ: Flow cytometric enrichment for respiratory epithelial cells in sputum. Cytometry A 2004;60:1-7. 